\title{
The Future of Family Medicine Residency Training is Our Future: A Call for Dialogue Across Our Community
}

Warren P. Newton, MD, MPH, Andrew Bazemore, MD, MPH, Michael Magill, MD, Karen Mitchell, MD, Lars Peterson, MD, PhD, and Robert L. Phillips, MD, MPH

( J Am Board Fam Med 2020;33:636-640.)

How should Family Medicine residencies evolve? This spring, even as COVID-19 highlighted US inattention to robust generalism in health care delivery and physician workforce, the Accreditation Council for Graduate Medical Educution (ACGME) announced plans to develop a major revision of the Family Medicine residency guidelines. The ACGME Family Medicine writing group, led by Stacy Potts, MD, will convene in October 2020, with the formal process beginning in early 2021 .

This is a big deal. Residency matters: habits imprinted in residency endure for many years. Pharmaceutical choices developed in residency foretell graduates' prescribing patterns for their entire careers. Operative complications in residency programs predict graduates complications ${ }^{1}$ years later and overall cost of care provided by graduates is imprinted in residency and lasts for at least 15 to 20 years. ${ }^{2}$ In addition, ACGME major revisions happen rarely: the last became effective in 2006! Given that residents trained under these guidelines will practice to 2060 and beyond, this revision will determine the shape and promise of Family Medicine for the next generation.

In December 2019, as a part of its strategic plan, the American Board of Family Medicine (ABFM) began discussion of priorities for the new residency guidelines and sought input from the Family Medicine

From the American Board of Family Medicine, Lexington, KY (WPN, AB, MM, LP, RLP); Department of Family Medicine, University of North Carolina, American Academy of Family Physicians, Chapel Hill, NC (WPN); American Academy of Family Physicians, Leawood, KS (KM).

Funding: None.

Conflicts: None.

Corresponding author: Warren P. Newton, MD, MPH, American Board of Family Medicine, 1648 McGrathiana Pkwy, Ste 550, Lexington, KY 40511-1247 (E-mail: wnewton@theabfm.org).
Leadership Council, the American Academy of Family Physicians (AAFP) Commission on Education, and the Boards of Association of Departments of Family Medicine (ADFM), Society of Teachers of Family Medicine (STFM), and Association of Family Medicine Residency Directors (AFMRD). With our partner organizations - the AAFP, AFMRD, ADFM, STFM, North American Primary Care Research Group (NAPCRG), and American College of Osteopathic Family Physicians (ACOFP)—we now urge our larger community-front-line clinicians, resident directors and faculty, residents and the patients, communities, employers, and health systems who will benefit from a robust family medicine role. This is about the future of our specialty.

As a starting place for dialog, ABFM believes our specialty should consider 6 key questions, listed in Table 1. American health care is transforming dramatically, driven by health system consolidation and physician employment, and accelerated by genomics, augmented intelligence and, especially, COVID-19. We now have a once-in-a-lifetime opportunity to rethink health care and residency education. ABFM starts from the premise that the personal physician ${ }^{3}$ should play a critical role in rebuilding a health system that can address the Triple Aim. Given trends toward subspecialization in internal medicine and pediatrics, ${ }^{4-6}$ we foresee Family Physicians making up an increasing share of generalist physicians, while recognizing the unique roles that general internists and community pediatricians continue to play in many communities. We also anticipate increasing delivery of primary care in teams inclusive of many other clinicians-from NPs/DNPs and PAs to mental health providers and community health workers-and that our residency programs must prepare us for that future. 
Table 1. Fundamental Questions for the Major Revision of Family Medicine Residency Guidelines

What does society need from the personal physicians of the future?

What should we teach?

How should we teach?

How will we prepare graduates for practice over their lifetimes?

What is the right balance between innovation and regulation?

How can we improve the accountability of residency education?

\section{What Does Society Need from the Personal Physicians of the Future?}

Perhaps the most important question for us to address is: what does society need from personal physicians of the future? As a specialty, Family Medicine was a child of the 1960s', compelling social need for access to personal physicians in the community. ${ }^{7}$ What does society need now, 50 years later? It has become increasingly clear that the outcomes of American health care are poor. Despite much higher investment in health care than European countries, we are sicker and die earlier across most diseases and all ages. ${ }^{8}$ Despite a robust economic expansion and health care reform, life expectancy has been dropping since 2014. ${ }^{9}$ And COVID-19 has laid bare the inequities of health care and the lack of integration of primary care into the health care system.

What clinical problems should we organize Family Medicine training around? After COVID19, few would argue against addressing emerging infectious disease or a robust linkage between primary care and public health. Multimorbidity remains the greatest driver of mortality, morbidity and cost; substance abuse and mental health represent compelling unmet needs. ABFM welcomes discussion of additions and priorities.

It is also important to consider the core functions of primary care. In the 2 generations since our founding, a rich literature has emerged linking the core functions of primary care-first-contact care, continuity, comprehensiveness, coordination, and connection to community-to population health and cost effectivess. ${ }^{10}$ But how do they translate to the 21st century? The Family Medicine for America's Health developed a definition of what the Family Physician of the future should be. ${ }^{11}$ But what does "first-contact care" mean when many first contacts occur with strangers by video? What does continuity mean in the age of telehealth? What should comprehensiveness look like, given both the declining scope of practices of Family Physicians ${ }^{12}$ and emerging obstetric deserts ${ }^{13}$ and the dramatic value of Family Physicians flexing scope during the pandemic? What does coordination of care mean in an age of plentiful care managers without personal connection to patients? And, finally, what should our commitment to community mean as we work in communities to change lifestyles and address implicit bias and disparities? The answers should inform our residency training guidelines.

\section{What Should we Teach?}

There is an important distinction between education, with its implication of the development of habits of mind across a lifetime, and training, with its implications of specific knowledge and tasks that are bound to the current context. Residency involves both. ABFM emphasizes education, given the many roles our graduates play over their careers and the need for adaptability to changes in health care and society. Core competencies are thus critical, but residencies must also emphasize the curricula needed for the present.

What core competencies should residencies teach? In 2002, the ACGME and $\mathrm{ABMS}^{14}$ identified 6 core competencies for all specialties: medical knowledge, patient care and procedural skills, interpersonal and communication skills, practice-based learning and improvement, systems-based practice and professionalism. Now, in 2020, given great unmet social needs and the dramatic changes in health care, are these competencies still appropriate and sufficient? Should population-based care be called out explicitly? And to what extent should these competencies be reframed in the light of the dramatic changes in health care? Should professionalism change when most Family Physicians are employed? How does communication change as we emphasize partnership with patients, include tele-video, and work in large systems and with communities?

Beyond fundamental competencies, what new curricula should all residencies require? Educators and policy makers have nominated integrated behavioral health, population health, genomics, and medication-assisted therapy. Employers and other stakeholders identify the need for expertise in teamwork, implementation of augmented intelligence, and tools such as point of care ultrasound, geospatial mapping, and predictive analytics. What topics 
are important to enough to be relevant for 20 to 30 years - and mandated for all residencies? How do we balance mandates with the flexibility needed for residencies to meet community needs and residents to pursue personal interests? ABFM welcomes discussion of priorities.

\section{How Should we Teach?}

Closely related to what we teach is how we teach. Fifty years ago, family medicine pioneered formal community-based education. Our residencies included many novel elements, including behavioral health, practice management, and formal educational objectives. Given the growth of learning science since 1969, how should we change the way we teach? In formal didactics, for example, there is compelling evidence that active learning is dramatically superior to passive learning ${ }^{15-17}$ and yet most continuing medical education (CME) and residency didactics are taught passively.

More challenging is our response to the competency-based medical education movement. ${ }^{18}$ On the face of it, who can argue with competency-based education? But, implementing competency-based education is more challenging than voicing the slogan. It is not clear that increasing focus on competency assessment in medical school has improved the competence of entering residents! One of the first models of competency-based residency education was in orthopedics ${ }^{19}$ - but how should a generalist discipline like Family Medicine operationalize? Diabetic care includes hundreds of separate competencies, making assessing and tracking impossible. What is the right balance between assessing individual competencies and time/experience? ${ }^{20}$

How long should residency education be? Worldwide there is great variation in duration of Family Physician training. The ABFM has funded a formal evaluation of a 4-year residency programs. The evaluation team is now reporting out on applications, finances, preparation for practice, scope, and core knowledge. We believe the duration and the structure of our clinical education is a critical issue, and the major revision gives us our last opportunity for 15 years.

\section{How Will we Prepare Graduates for Practice over Their Lifetimes?}

Our residency graduates will practice for 30 to 40 years. Over that time, the science underlying practice will change, as will the basic organization and financing of health care-and the graduates themselves will move and change their practices over the time. How do we prepare them for those changes? A common answer has been to emphasize critical appraisal and keeping up to date. This is important but likely insufficient: the pandemic has demonstrated the importance of family physicians and their trainees playing many very different roles, from tele-visits and COVID-19 diagnostic tents to inpatient management to community tracing. This is not just knowledge! What components of our current residencies built the flexibility and tenacity so prominent in in the past 4 months?

\section{What is the Right Balance between Innovation and Regulation?}

A major issue for our specialty is balance between innovation and regulation. The original guidelines for Family Medicine were 4 pages long and emphasized innovation, and ABFM has funded 2 national trials of innovation in residency education. $^{21,22,23}$ Quality control is important, however. Our residencies are growing at about 3.5\% per year ${ }^{24}$-even as the ACGME has changed its oversight strategy to annual data reporting and fewer site visits. ABFM hears anecdotes that occasional graduates are not able to perform important clinical tasks, such as managing attention deficit or recognizing an acutely ill patient, and ACGME data suggest that many residents do not achieve proficiency in 1 or more milestones. ABFM is delighted that our partners in the ACGME will make the evidence available to our community as a part of this process.

\section{How Can we Improve the Accountability of Residency Education?}

A final issue is the social accountability of our graduate medical education enterprise. At the local level, residencies must adapt their practices and curricula to changing conditions. How effective has the residency continuing quality improvement process been? Have clinical care and training improved? Do our current residency guidelines, and those of sponsoring institutions need adjustment to strengthen this function? 
More broadly, given the public interest in graduate medical education, it is important to examine overall system of graduate medical education accountability. Substantial public monies, through direct and indirect GME payments, Medicaid (in most states), and Medicare and Medicaid clinical revenues fund graduate medical education. Yet, as many have argued, ${ }^{25,26}$ the current GME system is often unmoored from the needs of the public. ABFM believes that there should be transparent linking of public funds to the needs of communities and the broader public. Major reform is needed, as the then Institute of Medicine has concluded. When will the right time be?

\section{Where Do we Go from Here?}

These are challenging questions, both to bring evidence to bear on and to engage in meaningful dia$\log$ with a large and diverse community. It is even more challenging to do in 6 months during a pandemic which impairs connection and distracts communication. But we have much more evidence and many more tools for dialog now than our predecessors did in the 1960s!

To provide the background evidence for the specialty, ABFM will work its partners at the Robert Graham Center, the ACGME and individual researchers to make the evidence available widely. But evidence by itself is insufficient. The "Family of Family Medicine"-the AAFP, the ACOFP, ADFM, AFMRD, STFM, and NAPCRG, in addition to ABFM - is working to organize discussions across the specialty through the summer and fall of 2020. In late fall, we will hold a national summit, in which input from our discussions will be brought to bear. We also plan a dedicated journal issue to frame the evidence and our discussions.

Our overall goal is to inform the deliberations of the ACGME writing committee. Our community needs to keep in mind understand that the ACGME is independent and must make its own decisions., But this fall's dialog and the national summit will provide important context and key themes for them. Input from the specialty is also important for $\mathrm{ABFM}$ as it considers requirements for Board eligibility.

We welcome your voices!

To see this article online, please go to: http://jabfm.org/content/ 33/4/636.full.

\section{References}

1. Asch DA, Nicholson S, Srinivas S, Herrin J, Epstein AJ. Evaluating obstetrical residency programs using patient outcomes. JAMA 2009;302: 1277-83.

2. Chen C, Petterson S, Phillips R, Bazemore A, Mullan R. Spending Patterns in region of residency training and subsequent expenditures for care provided by practicing physicians for Medicare beneficiaries. JAMA 2014;312:2385-93.

3. Fox TF, Cantab MD, Glasg L. The personal doctor and his relation to the hospital observations and reflections on some american experiments in general practice by groups. Lancet 1960;275:743-60.

4. Freed GL, Moran LM, Van KD, Leslie LK. Research Advisory Committee of the American Board of Pediatrics. Current workforce of pediatric subspecialists in the United States. Pediatrics 2017;139:e20163604.

5. Dalen JE, Ryan KJ, Alpert JS. Where have the generalists gone? They became specialists, then subspecialists. Am J Med 2017;130:766-8.

6. Smart DR. Physician characteristics and distribution in the US-2013. Chicago, IL: American Medical Association; 2012.

7. Newton WP. Charting the future of board certification. J Am Board Fam Med 2020. In press.

8. U.S. health in international perspective: shorter lives, poorer health. Washington, DC: National Research Council and Institute of Medicine of the National Academies; 2013.

9. Woolf SH, Schoomaker H. Life expectancy and mortality rates in the United States, 1959-2017. JAMA 2019;322:1996-2016.

10. Macinko J, Starfield B, Shi L. Contribution of primary care systems to health outcomes within Organization for Economic Cooperation and Development (OECD) countries, 1970-1998. Milbank Q 2005;83: 457-502.

11. Phillips RL, Brungardt S, Lesko SE, et al. The future role of the family physician in the united states: a rigorous exercise in definition. Ann Fam Med 2014;12:250-5.

12. Anastasia J, Coutinho AJ, Phillips RL, Peterson LE. Intended vs reported scope of practice. JAMA 2016;315:2234-5.

13. Cullen J. New AAFP initiative addresses rural health care crisis. Ann Fam Med 2019;17:471-2.

14. Batalden P, Leach D, Swing S, Dreyfus H, Dreyfus $\mathrm{S}$. General competencies and accreditation in graduate medical education. Health Aff (Millwood) 2002;21:103-11.

15. Zakrajsek T. Developing effective lectures. Vol 1. Washington, DC: American Psychological Society; 1998.

16. Zakrajsek T. All learning is an active process: rethinking active/passive learning debate. 2016. 
https://www.scholarlyteacher.com/post/all-learningis-an-active-process. Accessed May 28, 2020.

17. Zakrajsek T. Reframing the lecture versus active learning debate: suggestions for a new way forward. Educ Health Prof 2018;1:1.

18. Holmboe E, Sherbino J, Englander R, Snell L, Frank JR. Call to action: the controversy of and rationale for competency-based medical education. Med Teach 2017;39:574-81.

19. Hodges BD. A tea-steeping or i-Doc model for medical education? Acad Med 2010;85: S34-S44.

20. Nousiainen MT, Mironova P, Hynes M, et al. Eight-year outcomes of a competency-based residency training program in orthopedic surgery. Med Teach 2018;40:1042-54.

21. Accreditation Council for Graduate Medical Education. About us: innovation. https://www.
acgme.org/About-Us/Overview. Accessed May 26, 2020.

22. Carney PA, Eiff MP, Waller E, Jones SM, Green L. Redesigning residency training: summary findings from the Preparing the Personal Physician for Practice (P4) project. Fam Med 2018;50:503-17.

23. Eiff MP, Ericson A, Uchison EW, et al. A comparison of residency applications and match performance in 3-year vs. 4-year family medicine training programs. Fam Med 2019;51:641-8.

24. Newton WP, Baxley EG. Numbers matter. Ann Fam Med 2019;17:280-2.

25. Newton WP, Wouk N, Spero JC. Improving the return on investment of graduate medical education in North Carolina. NCMJ 2016;77:121-7.

26. Institute of Medicine. Graduate medical education that meets the nation's health needs. Washington, DC: The National Academies Press; 2014. 